\title{
Effects of Salidroside on Cobalt Chloride-Induced Hypoxia Damage and mTOR Signaling Repression in PC12 Cells
}

\author{
Xiaoyong Zhong, ${ }^{a, b, d}$ Ruhui Lin, ${ }^{c, d}$ Zuanfang Li, ${ }^{d}$ Jingjie Mao, ${ }^{d}$ and Lidian Chen*,a,b,c \\ ${ }^{a}$ College of Rehabilitation Medicine, Fujian University of Traditional Chinese Medicine; ${ }^{b}$ Key Laboratory of TCM \\ Rehabilitation of State Administration of Traditional Chinese Medicine, Fujian University of Traditional Chinese \\ Medicine; ${ }^{c}$ MOE Key Laboratory of Traditional Chinese Medicine on Osteology \& Traumatology and Exercise \\ Rehabilitation, Fujian University of Traditional Chinese Medicine; and ${ }^{d}$ Academy of Integrative Medicine, Fujian \\ University of Traditional Chinese Medicine; 1 Huatuo Road, Minhou Shangjie, Fuzhou, Fujian 350122, P. R. China. \\ Received January 29, 2014; accepted April 27, 2014
}

Salidroside (SA), a phenylpropanoid glycoside isolated from Rhodiola rosea $\mathrm{L}$., has been documented to exert a broad spectrum of pharmacological properties, including protective effects against neuronal death induced by various stresses. To provide further insights into the neuroprotective functions of SA, this study examined whether SA can attenuate cobalt chloride $\left(\mathrm{CoCl}_{2}\right)$-induced hypoxia damage and mammalian target of rapamycin (mTOR) signaling repression in PC12 differentiated cells. Differentiated PC12 cells were exposed to $\mathrm{CoCl}_{2}$ for $12 \mathrm{~h}$ to mimic hypoxic/ischemic conditions and treated with $\mathrm{SA}$ at the same time, followed by electron microscopy and analysis of cell viability, intracellular reactive oxygen species (ROS) level, hypoxiainducible factor-1 $\alpha$ (HIF-1 $\alpha)$ level, and the regulated in development and DNA damage responses (REDD1)/ mTOR/ p70 ribosomal S6 kinase (p70S6K) signaling pathway. Our data indicated that SA can dramatically attenuate the ultrastructural damage of mitochondria induced by $\mathrm{CoCl}_{2}$ and significantly decrease $\mathrm{CoCl}_{2}$ induced ROS production. Moreover, phosphorylated mammalian target of rapamycin (p-mTOR) was significantly reduced by $\mathrm{CoCl}_{2}$, and this inhibition was relieved by the treatment of SA in PC12 cells, as evidenced by immunoblot and quantitative reverse transcription-polymerase chain reaction (qRT-PCR) analyses. The $\mathrm{SA}$ effects were blocked by pretreatment of $\mathrm{RAD001}$. The results indicate that $\mathrm{SA}$ can rescue $\mathrm{CoCl}_{2}$-induced repression of REDD1/mTOR/ p70S6K signal transduction in PC12 cells. Our data demonstrate that SA is able to attenuate $\mathrm{CoCl}_{2}$-induced hypoxia damage and $\mathrm{mTOR}$ signaling repression, suggesting that SA may protect brain neurons from ischemic injury through mTOR signaling, and provide new insights into the prevention and treatment of cerebral ischemic. cell

Key words salidroside; ischemic; mammalian target of rapamycin (mTOR); hypoxia; cobalt chloride; PC12

Focal cerebral ischemia or stroke is characterized by obstruction of blood flow to the brain, resulting in deficient supply of oxygen, glucose, serum, and nutrient that are indispensable for the energy generation. Since central nervous system is most susceptible to hypoxia conditions, the continuous oxygen and energy deprivation results in cognitive disturbances and decreased motor control, leading to fainting, long term loss of consciousness, coma, seizures, cessation of brain stem reflexes, and brain death. Ischemic stroke is currently a leading cause of disability and mortality in the aged population, due to limited medication and therapy, and new therapeutic strategies for this devastating disease are urgently needed.

Recently, the role of mammalian target of rapamycin (mTOR) signaling in neurodegenerative and cerebrovascular diseases has attracted great attention. ${ }^{1)}$ As a serine/threonine kinase, mTOR activation can mediate broad biological activities that include translation initiation, transcription, cytoskeleton organization, cell growth, and proliferation as well as cell survival. ${ }^{2)}$ Based on the ability of mTOR to prevent neuronal apoptosis, inhibit autophagic cell death, promote neurogenesis, and improve angiogenesis, mTOR may acquire the capability of limiting the ischemic neuronal death and promoting the neurological recovery. ${ }^{1)}$ Consequently, regulation of mTOR activity has emerged as a potential therapeutic strategy for ischemic stroke. It has been shown that mTOR activity is repressed by hypoxia, ${ }^{3)}$ and the mTOR signaling repression is

The authors declare no conflict of interest.

* To whom correspondence should be addressed. e-mail: cld@fjtcm.edu.cn maintained by the hypoxia-inducible factor-1 $\alpha$ (HIF-1 $\alpha$ ), which up-regulates regulated in development and DNA damage responses (REDD1) in a number of cell lines including PC12 cells in response to hypoxia. ${ }^{4)}$ And REDD1 is essential for the inhibition of mTOR signaling pathway. ${ }^{5,6)}$

Cobalt chloride $\left(\mathrm{CoCl}_{2}\right)$ is well known as a hypoxia-inducing agent to mimic hypoxic/ischemic conditions, including generation of reactive oxygen species (ROS) and up-regulation of hypoxic-specific genes such as the hypoxia-inducible transcription factor-1a (HIF-1a). ${ }^{7,8)}$ The rat pheochromocytoma cell line PC-12 is catecholaminergic, excitable, and widely used for cell signaling and neurochemical studies. ${ }^{9,10)}$ In this study, we find that PC12 cells provide a useful in vitro system for the study of hypoxia-induced neuronal injury upon exposure to $\mathrm{CoCl}_{2} \cdot{ }^{11,12)}$

Salidroside (SA), a natural compound from Rhodiola rosea L., is a major active ingredient responsible for most pharmacological effects of Rhodiola, such as anti-oxidative, anti-aging, anti-inflammatory, anti-cancer, anti-fatigue and anti-depressant activities. ${ }^{13-19)}$ Increasing evidence suggests that SA may have neuroprotective effects in injured brain. SA can reduce the degree of cerebral edema and the brain infarct size of rats with global cerebral ischemia, relieve the metabolism abnormity of free radicals and improve the function of cognition as well as behavioral and histological outcomes. ${ }^{20-22)}$ Furthermore, several in vitro studies have shown that SA protects against neuronal apoptotic death induced by various stimuli, such as glutamate, $\mathrm{H}_{2} \mathrm{O}_{2}$, hypoglycemia/serum limitation, $\mathrm{MPP}^{+}$, and 
$\mathrm{CoCl}_{2}$, via antioxidative action or upregulation of survival signals, such as the Bcl-2/Bax ratio, Akt phosphorylation, and maintenance of mitochondrial integrity. ${ }^{23-33)}$ In addition, it has been reported that SA may regulate mTOR signaling in cultured human umbilical vein endothelial cells (HUVECs) or in bladder cancer cell lines. ${ }^{34,35)}$ However, whether the neuroprotective effects of SA involve regulation of the mTOR signaling pathway in PC12 cells is still unknown.

To gain further insights into the neuroprotective functions of SA, we have used the PC12 cell model and investigated the underlying mechanism by which SA may protect the cells from $\mathrm{CoCl}_{2}$-induced damage.

\section{MATERIALS AND METHODS}

Materials SA (purity $>99 \%$ ) was obtained from the National Institute for the Control of Pharmaceutical and Biological Products (Beijing, China). Mouse 2.5S nerve growth factor (NGF) was purchased from Promega (Madison, WI, U.S.A.). Cobalt Chloride $\left(\mathrm{CoCl}_{2}\right)$, 4',6-diamidino-2-phenylindole (DAPI), 3-(4,5-dimethylthiazol-2-yl)-2,5-diphenyltetrazolium bromide (MTT) were purchased from Sigma-Aldrich (St. Louis, MO, U.S.A.). Dulbecco's modified Eagle's medium (DMEM), fetal calf serum (FCS) and horse serum were purchased from Life Technologies (Gaithersburg, MD, U.S.A.). The bicinchoninic acid (BCA) protein assay kit, ROS assay kit was obtained from Beyotime Institute of Biotechnology (Shanghai, China). HIF-1 $\alpha$ antibody were from Santa Cruz Biotechnology (Santa Cruz, CA, U.S.A.). The anti-mTOR, anti-phospho-mTOR, anti- p70 S6 Kinase (49D7), anti-Phosphop70 S6 Kinase (Thr389) Rabbit mAb antibodies, rabbit-immunoglobulin $\mathrm{G}$ (IgG) conjugated peroxidase and everolimus (RAD001) were purchased from Cell Signaling Technology (St. Louis, MO, U.S.A.). REDD1 Rabbit polyclonal antibody were purchased from Proteintech Europe Ltd. (Manchester, U.K.).

Cell Culture and Treatment $\mathrm{PC} 12$ cells were maintained as monolayer cultures in $25-\mathrm{cm}^{2}$ tissue culture flasks in complete medium, CM (DMEM supplemented with 10\% heatinactivated horse serum and 5\% heat-inactivated fetal bovine serum, $100 \mathrm{U} / \mathrm{mL}$ penicillin, $100 \mu \mathrm{g} / \mathrm{mL}$ streptomycin), in a humidified $5 \% \mathrm{CO}_{2}$ incubator at $37^{\circ} \mathrm{C}$. Cells were subcultured either in 96-well plates at a density of $1 \times 10^{4}$ cells/well for cell viability assay, in 6 -well plates $\left(1.6 \times 10^{5}\right.$ cells/ well $)$ for ROS determination, or in $100 \mathrm{~mm}$ diameter dish $\left(8 \times 10^{5}\right.$ cells/ dish) for all other experiments. PC12 cells were differentiated for $2 \mathrm{~d}$ before the treatment with $\mathrm{SA}$ or $\mathrm{CoCl}_{2}$ in low serum medium (LSM) (DMEM supplemented with 1\% horse serum, $100 \mathrm{U} / \mathrm{mL}$ penicillin, $100 \mu \mathrm{g} / \mathrm{mL}$ streptomycin), in the presence of $50 \mathrm{ng} / \mathrm{mL} \mathrm{NGF}$, followed by various functional tests in the differentiated cells as described below.

Measurement of Cell Viability Cell viability was measured using the MTT assay. $\mathrm{CoCl}_{2}$ was applied at various concentrations $(100,200,300,400,500,600,700 \mu \mathrm{M})$ for 12,24 , and $36 \mathrm{~h}$ to investigate the effective concentrations of $\mathrm{CoCl}_{2}$ for induction of neurotoxicity. After the treatment, $10 \mu \mathrm{L} \mathrm{MTT}$ solution $(5 \mathrm{mg} / \mathrm{mL}$ in phosphate buffered saline (PBS)) was added to each well, the plates were incubated at $37^{\circ} \mathrm{C}$ for $4 \mathrm{~h}$, the culture medium containing MTT was removed and $100 \mu \mathrm{L}$ dimethyl sulfoxide (DMSO) was added to each well to dissolve the formazan. The absorbance was measured at $570 \mathrm{~nm}$ using an enzyme-linked immunosorbent assay (ELISA) reader (BioTek, Model EXL800, U.S.A.).

With the appropriate concentration of $\mathrm{CoCl}_{2}$, differentiated PC12 cells were subjected to SA $(30,60,90,120 \mu \mathrm{M})$ treatment followed by the MTT assay described above, we determined the effective concentrations of SA and $\mathrm{CoCl}_{2}$ as $90 \mu \mathrm{M}$ and $400 \mu \mathrm{M}$, respectively, which were used in the following experiments.

Electron Microscopy Cells were fixed in $2.5 \%$ glutaraldehyde in PBS (pH 7.3). Following treatment in $1 \%$ osmium tetroxide solution (OsO4), 2\% uranylacetate (UA) and dehydration in ethanol and acetone series, the samples were embedded in epoxy resin and polymerized $48 \mathrm{~h}$ at $60^{\circ} \mathrm{C}$. Ultrathin sections were made with a glass knife on an ultramicrotome and picked up on copper net (100 mesh). Sections on grids were post-stained for 2 min with $1 \%$ UA and 6 min with $1 \%$ lead citrate by floating them on single drops of the staining solution at room temperature, then rinsed in deionized water and dried. Sections were observed by using a H7650 electron microscope (Hitachi, Tokyo, Japan).

Measurement of Intracellular ROS The ROS level was determined with a ROS assay kit (Beyotime, Shanghai, China). In brief, after cell treatments for $12 \mathrm{~h}$, as indicated, cells were incubated with $20 \mu \mathrm{m}$ dichloro-dihydro-fluorescein diacetate (DCFH-DA) at $37^{\circ} \mathrm{C}$ for $30 \mathrm{~min}$ in the dark, and then gently rinsed with DMEM 3 times. The fluorescence of DCFH-DA was excited at $480 \mathrm{~nm}$ and detected at $530 \mathrm{~nm}$ by flow cytometry (FACScalibur, BD Bioscience, San Jose, CA, U.S.A.).

mRNA Quantitation by Quantitative Polymerase Chain Reaction (PCR) Analysis Total RNAs were extracted with TRIZOL ${ }^{\circledR}$ Reagent (Invitrogen, Barcelona, Spain), and mRNAs were transcribed to cDNAs using the PrimeScripti ${ }^{\circledR}$ RT reagent kit with gDNA Eraser (TaKaRa) and used as template for the quantitative PCR assay (Kit SYBR ${ }^{\circledR}$ Premix Ex $\mathrm{Taq}^{\mathrm{TM}}$, TaKaRa BIO Inc.). PCR was performed in a 7500 fast Real-Time system (ABI, CA, U.S.A.) and the results were analyzed with Software provided by 7500 fast system. Data were normalized with P0 levels and expressed as the ratio between hypoxia and control. The primers used in these reactions are listed in Table 1. ${ }^{4}$ )

Western Blot Analysis Cell lysates $(30 \mu \mathrm{L})$ were resolved by sodium dodecyl sulfate-polyacrylamide gel electrophoresis (SDS-PAGE) and proteins were electrophoretically transferred onto polyvinylidene difluoride (PVDF) membranes. Membranes were blocked for $120 \mathrm{~min}$ in $5 \% \mathrm{w} / \mathrm{v}$ bovine serum albumin (BSA) at room temperature and then incubated with monoclonal antibodies for the indicated proteins or for $\beta$-actin as a loading control over night at $4^{\circ} \mathrm{C}$. After washing in TBS with $0.25 \%$ Tween-20 (TBST), membranes were incubated

Table 1. Primer Used for the Quantitative PCR

\begin{tabular}{lll}
\hline \hline Target & Name & Sequence \\
\hline P0 & 5' P0 & 5'-CCTCATATCCGGGGGAATGTG-3' \\
& 3' P0 & 5'-GCAGCAGCTGGCACCTTATTG-3' \\
HIF-1 $\alpha$ & 5' HIF-1 $\alpha$ & 5'-AGTGTACCCTAACTAGCCG-3' \\
& 3' HIF-1 $\alpha$ & 5'-TTCACAAATCAGCACCAAGC-3' \\
REDD1 & 5' REDD1 & 5'-TCTGGACCCCAGTCTAGTGC-3' \\
& 3' REDD1 & 5'-ACCAGGGACCAAGGAAGAGT-3' \\
\hline
\end{tabular}


with the horseradish peroxidase-conjugated secondary antibody for $2 \mathrm{~h}$ at room temperature and the membranes were washed again in TBST. The specific protein bands were analyzed with enhanced eyoECL Plus reagents (Beyotime, Shanghai, China) and scanned with a Storm PhosphorImager (Bio-Rad Chemi Doc XRS+, U.S.A.).

Statistical Analysis All results were the means of triplicate samples and the data were analyzed using the SPSS package for Windows (Version 16.0). Statistical analysis of the data was performed with Student's $t$-test and ANOVA. Differences with $p<0.05$ were considered statistically significant.

\section{RESULTS}

Protective Effect of $\mathrm{SA}$ on $\mathrm{CoCl}_{2}$-Induced Loss of Cell Viability MTT assay indicated that exposure of PC12 cells to $\mathrm{CoCl}_{2}$ at different concentrations $(100,200,300,400,500$, $600,700 \mu \mathrm{M})$ for 12,24 , and $36 \mathrm{~h}$ caused significant decreases in cell viability, and the cell viability loss exhibited a dose- dependent manner (Fig. 1b). Exposure to $400 \mu \mathrm{M} \mathrm{CoCl}_{2}$ for $12 \mathrm{~h}$ resulted in nearly $50 \%$ decrease in cell viability $(54.8 \pm$ $9.4 .9 \%$ viable cells) as compared to untreated control cells (100\% viability). So in the following experiments, the $400 \mu \mathrm{M}$ $\mathrm{CoCl}_{2}$ treatment for $12 \mathrm{~h}$ was used to mimic hypoxic/ischemic conditions in PC12 cells. We also found that different treatment of SA $(30,60,90,120 \mu \mathrm{M})$ was able to protect cells from $\mathrm{CoCl}_{2}$-induced cell viability loss, with maximum protection (79.6 \pm 14.4 viable cells) at $90 \mu \mathrm{M}$ (Fig. 1c).

SA Blocks Hypoxia-Induced Cell Death upon $\mathrm{CoCl}_{2}$ Treatment It's well known that $\mathrm{CoCl}_{2}$ induces apoptosis in PC12 cells through ROS. ${ }^{36)}$ In this regard, the $\mathrm{CoCl}_{2}$-induced $\mathrm{PC} 12$ cell death was triggered within $12 \mathrm{~h}$ with $400 \mu \mathrm{M} \mathrm{CoCl}$ treatment, corresponding to the cell viability loss (Fig. 1b) and morphological changes under light microscopy (date not shown). Furthermore, we used electron microscopy to determine the ultrastructural changes in the cell upon $\mathrm{CoCl}_{2}$ treatment, the results showed that nucleolus disappeared, condensed chromatin relocalized to the inner side of an in- a<smiles>OCC1O[C@H](OCCc2ccc(O)cc2)[C@@H](O)[C@H](O)[C@H]1O</smiles>

C

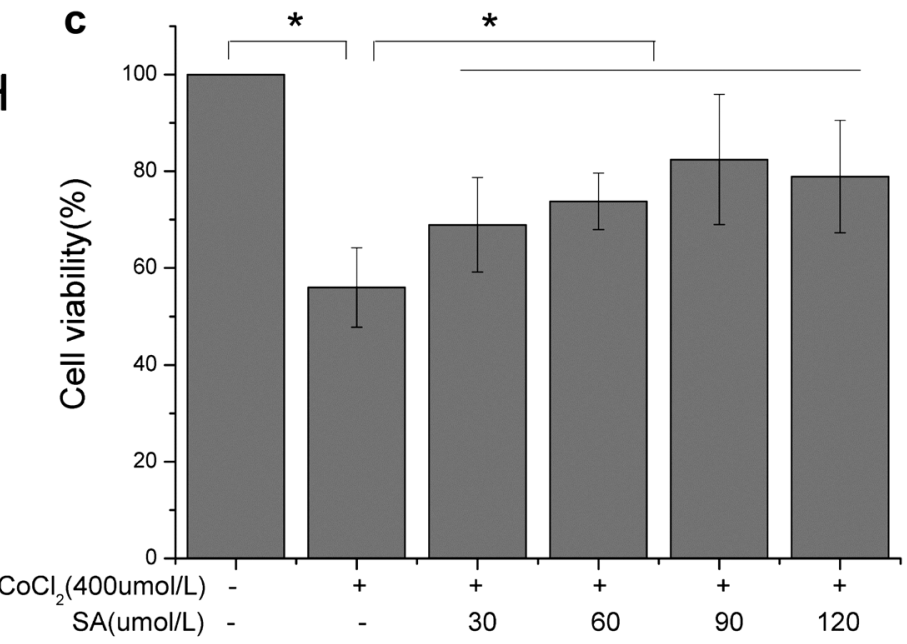

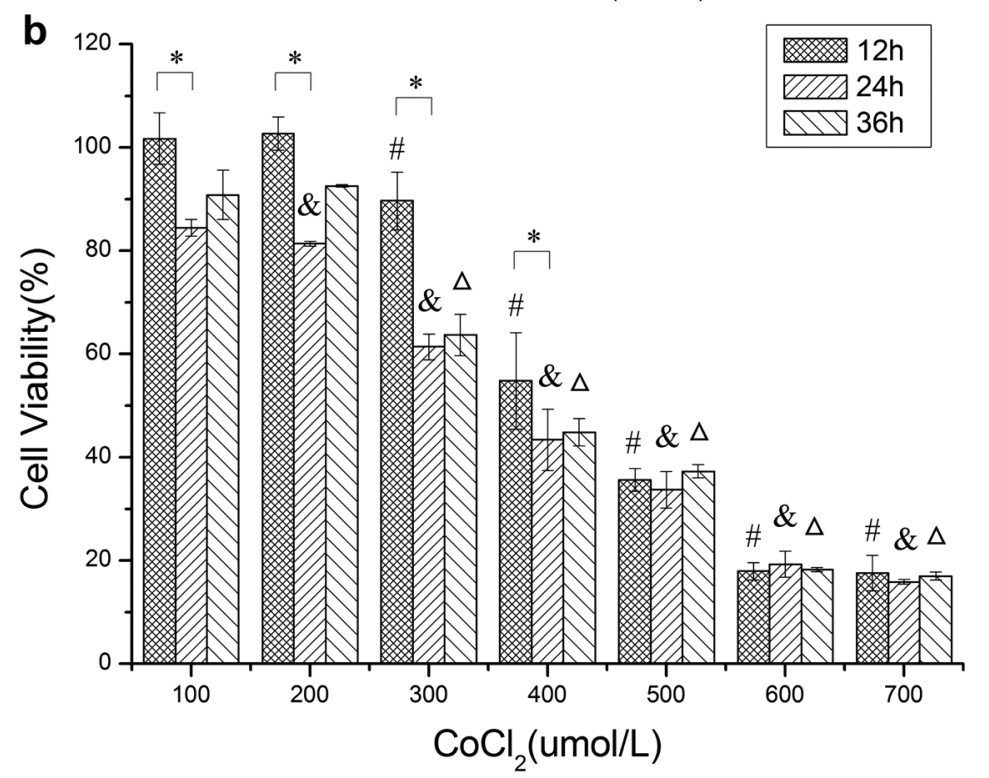

Fig. 1. Protective Effect of SA on $\mathrm{CoCl}_{2}$-Induced Loss of Cell Viability

(a) Chemical structure of SA ( $p$-hydroxyphenethyl- $\beta$-D-glucoside). (b) PC12 cells were exposed to $\mathrm{CoCl}_{2}(100,200,300,400,500,600,700 \mu \mathrm{M})$ for 12,24 , and $36 \mathrm{~h}$, and the cell viability was measured by MTT assay. (c) MTT assay after different cell treatments, which included exposure to $400 \mu \mathrm{M}$ CoCl $\mathrm{H}_{2}$ for $12 \mathrm{~h}$ without and with treatment of SA at $30,60,90,120 \mu \mathrm{m}$ for $12 \mathrm{~h}$ at same time, PC12 cells undergoing neither SA treatment nor CoCl, stimulation served as control. Results are mean \pm S.E.M. of four independent experiments; ${ }^{*} p<0.05$ by ANOVA. $\#, \&, \triangle, p<0.05$ indicate differences between different dose treatment of CoCl ${ }_{2}$ in $12 \mathrm{~h}, 24 \mathrm{~h}$, and $36 \mathrm{~h}$, respectively. 
tact nuclear membrane, and mitochondria were swollen with disintegration and lysis of the cristae in $\mathrm{CoCl}_{2}$-treated $\mathrm{PC} 12$ cells in comparison to untreated control cells (Fig. 2b). In this regard, SA significantly alleviated the $\mathrm{CoCl}_{2}$-induced ultrastructural changes characteristic of cellular damage (Fig. 2c).

Furthermore, we investigated the effects of SA on $\mathrm{CoCl}_{2}-$ induced elevation of ROS production in PC12 Cells. Flow cytometry with molecular probe DCFH-DA was used to monitor alterations in the intracellular ROS level. The results were evaluated by relative fluorescence units (RFU). As compared to control, exposure of differentiated $\mathrm{PC} 12$ cells to $\mathrm{CoCl}_{2}$ treatment significantly increased the RFU by $2.40 \pm 0.14$ fold (Fig. 3b), indicating an elevation of ROS production. SA treatment attenuated the $\mathrm{CoCl}_{2}$-induced increase in ROS production, as evidenced by a significant decline in the fluorescence intensity to $1.86 \pm 0.04$ (Fig. 3b).

The Neuroprotective Mechanism of SA Involves the REDD1/mTOR/p70S6K Signaling Pathway It is well known that hypoxia triggers oxidative stress and downregulates mTOR signal transduction, including generation of ROS and increased expression of HIF-1a, REDD1, etc., , $7,8,27,36)$ which represses mTOR signaling in PC12 cells in response to hypoxia. ${ }^{3-5)}$ We found a significant increase in the levels of HIF-1a $(0.45 \pm 0.02$ fold increase) and REDD1 $(0.62 \pm 0.02$ fold increase) (Fig. 4b, c) in the PC12 cells after a $12 \mathrm{~h}$ treatment by $400 \mu \mathrm{M} \mathrm{CoCl}$, and this up-regulation of HIF-1 $\alpha$ and REDD1 was attenuated by addition of SA $(90 \mu \mathrm{M})$ (Fig. 4b, c). Furthermore, our real-time qRT-PCR analysis showed that $\mathrm{CoCl}_{2}$ treatment increased the mRNA level of REDD1 but not HIF- $1 \alpha$ level (Figs. 4d, e). In contrast, SA treatment profoundly reduced the mRNA levels of both REDD1 and HIF-1 $\alpha$. Next we analyzed the phosphorylation status and levels of mTOR, p70S6K (Fig. 5a) by Western blot. As shown in Figs. 5b and c, a $12 \mathrm{~h} \mathrm{CoCl}_{2}$ treatment $(400 \mu \mathrm{M})$ showed a significant reduction in the levels of mTOR and p70S6K $(0.24 \pm 0.01$ fold, $0.39 \pm 0.1$ fold, respectively) compared with untreated control cells, and SA was able to attenuate the repression of mTOR, p70S6K to $0.41 \pm 0.02$ fold, $0.65 \pm 0.06$ fold $(p<0.05)$, respectively. However, when the cells were pretreated with $2 \mathrm{~nm}$ RAD001 (everolimus), an mTOR inhibitor, SA-induced increase in mTOR, p70S6K expression was almost blocked (Fig. 5). a

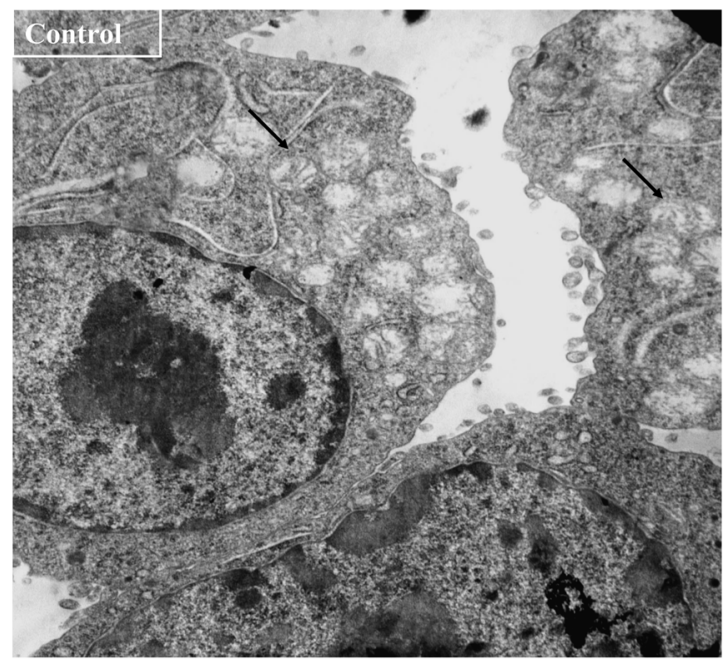

b

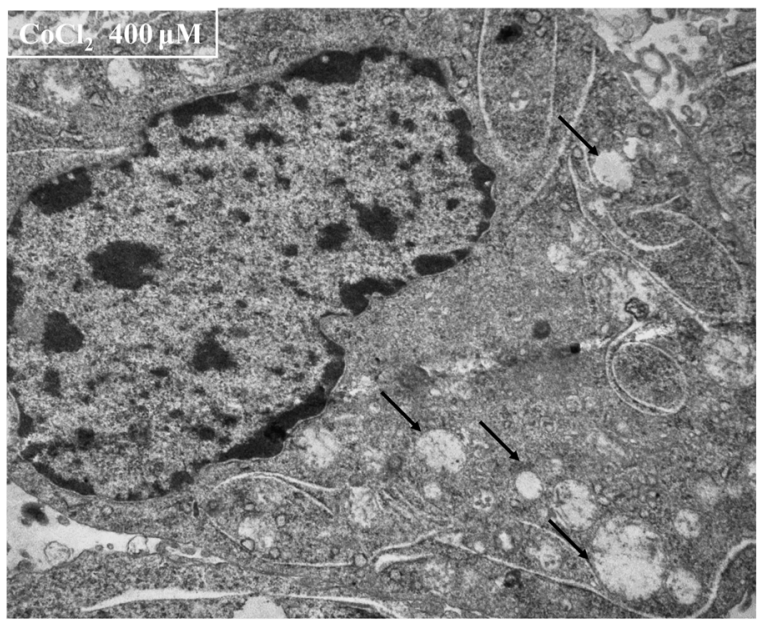

C

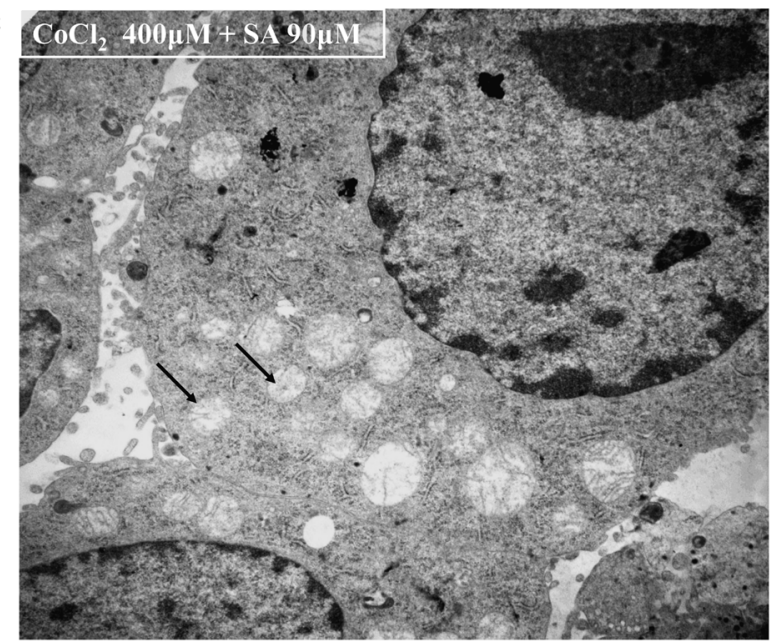

Fig. 2. Effect of $\mathrm{SA}$ on $\mathrm{CoCl}_{2}$-Induced Cell Damage Analyzed by Electron Microscopy

PC12 cells incubated in the absence (a) of $\mathrm{CoCl}_{2}$ showed a normal ultrastructural, whereas in the presence (b) of $400 \mu \mathrm{M} \mathrm{CoCl}{ }_{2}$ for $12 \mathrm{~h}$, showed a ultrastructural change with nucleolus disappeared, condensed chromatin localized to the inner side of an intact nuclear membrane, mitochondria (arrows) swollen with disintegration and lysis of cristae in PC12 cells. With the treatment of SA (c), SA group showed a slight apoptosis ultrastructural changes and drastic ultrastructural changes of mitochondrial compared with model group. The arrows indicate the ultrastructural change of mitochondria. 
a

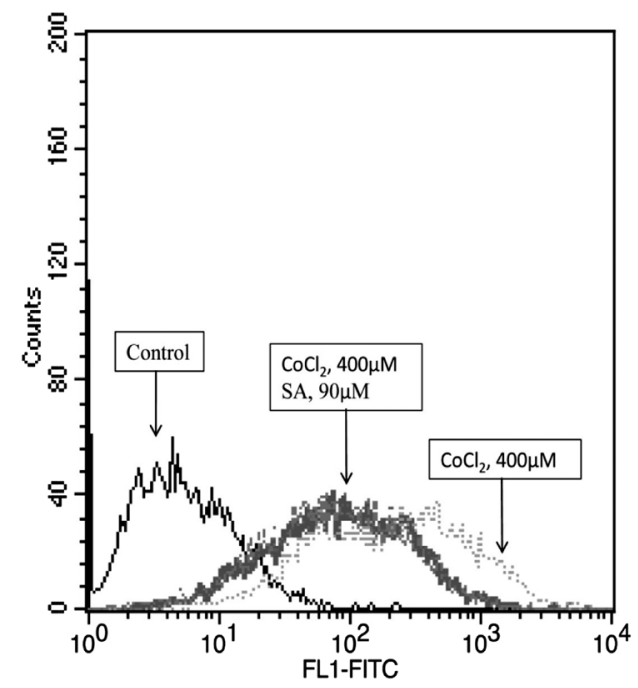

b

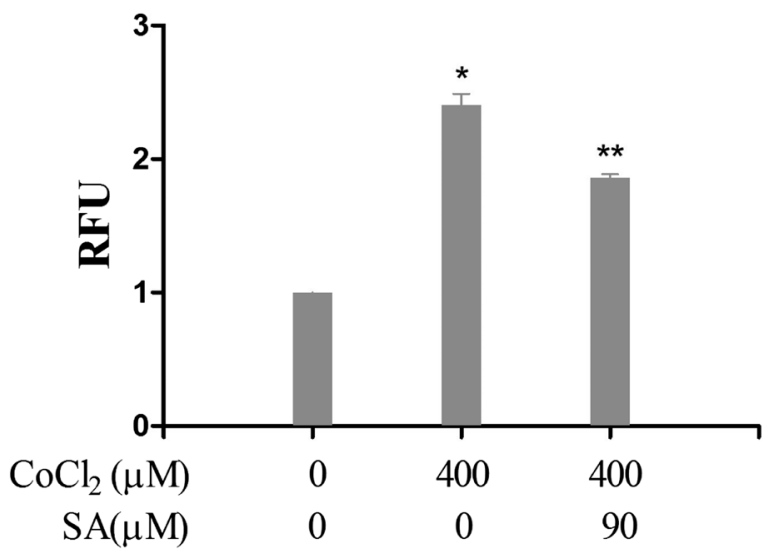

Fig. 3. Effect of SA on $\mathrm{CoCl}_{2}$-Induced ROS Production in PC12 Cells

ROS production in PC12 cells was measured by flow cytometry following DCFH-DA staining. FCM reuslts of 3 groups were overlayed in one picture (a). The results were evaluated by relative fluorescence units (RFU) (b). Results are mean \pm S.E.M. of three independent experiments; $* p<0.05$, compared with the control group (no treatment). ${ }^{* *} p<0.05$, compared with the group that treated with $\mathrm{CoCl}_{2}$ only.

\section{DISCUSSION}

Ischemic stroke is one of the major causes of mortality and long-term disability in aged population, and very few treatment options are available. ${ }^{37)}$ As such, developing new neuroprotective drugs and investigating the molecular mechanism of neuroprotection have become a major research focus in the field. SA, as a small-molecule compound of Rhodiola rosea L. with a defined chemical structure as phenol glycoside (Fig. 1a), has been documented to possess neuroprotective effects against neuronal damage induced by various insults. ${ }^{19-33)}$ However, the underlying mechanisms are still not well understood.

As a serine/threonine kinase, mTOR plays a central role in translation initiation, transcription, cytoskeleton organization, cell growth, and proliferation as well as cell survival. mTOR functions through mTORC1 and mTORC2 complexes and their multiple downstream substrates, such as eukaryotic initiation factor 4E-binding protein 1 (4EBP1), p70 ribosomal S6 kinase (p70S6K), sterol regulatory element-binding protein 1, serum-and gucocorticoid-induced protein kinase 1 , etc. ${ }^{2)}$ The two major well-established downstream targets of mTORC1 are p70S6K and 4EBP1. Active mTORC1 can activate p70S6K and the activation of $\mathrm{p} 70 \mathrm{~S} 6 \mathrm{~K}$ promotes mRNA biogenesis, translation of ribosomal proteins, and cell growth. ${ }^{38)}$ A large body of studies have revealed the neuroprotective effects of mTOR activity during cerebral ischemia. Administration of estradiol to adult female ovariectomied rats prior to focal cerebral ischemia significantly reduces infarct volumes and decreases apoptosis in the cerebral cortex and concurrently prevents ischemia induced-decrease in the expression of phosphorylated mTOR and p70S6K. ${ }^{39)}$ Depletion of S6K1 enhances oxygen glucose deprivation (OGD), an in vitro model of ischemia, induced injury in astrocytes. In contrast, repletion of S6K1 expression by adenoviral infection reduces cell injury. ${ }^{40)}$ Moreover, the absence of S6K expression in the brain increases infarct volume and mortality in mice follow- ing focal cerebral ischemia. ${ }^{40)}$ In addition, inhibition of mTOR activity by rapamycin decreases cell survival and increases apoptotic injury in neurons and microglia during OGD. ${ }^{41-43)}$ Erythropoietin, the hematopoietic growth factor and neuronprotectant, has been shown to protect microglia against OGD through enhancing mTOR activity and preventing mitochondrial cytochrome $c$ release, since inhibition of mTOR by using rapamycin abrogates the cytoprotection of erythropoietin. ${ }^{44)}$ Rapamycin can also increase the brain infarct size as well as increase the neurological deficit scores following focal cerebral ischemia in rats. ${ }^{41)}$ These studies suggest that the mTOR signaling pathway is involved in the underlying neuroprotective mechanisms during cerebral ischemia As increasing evidence suggests that SA may have neuroprotective effects in injured brain, ${ }^{20-22}$ we speculate that SA may exert the neuroprotective effects by regulating the mTOR signaling pathway.

In this study, we have shown that SA is capable of protecting $\mathrm{PC} 12$ cells against $\mathrm{CoCl}_{2}$-induced hypoxia damage by maintaining mTOR signaling activity, as evidenced by upregulated phosphorylation of mTOR, p70S6k. Furthermore, RAD001, also known as Everolimus, an immunosuppressant analog of rapamycin that can dephosphorylate mTOR downstream targets, can block the mTOR signaling activity maintained by SA. It has been shown that mTOR activity is repressed by hypoxia, and the mTOR signaling repression is maintained by HIF-1 $\alpha$, which up-regulates REDD1 in a number of cell lines including PC12 cells in response to hypoxia. ${ }^{3)}$ In this study, our date show that $\mathrm{CoCl}_{2}$ can inhibit the activity of mTOR through the up-regulation of REDD1 and HIF-1 $\alpha$ expression, as evidenced by Western-blot results. Although the mRNA level of HIF- $1 \alpha$ does not change with increased protein level, this may be caused by instantaneous induction of HIF- $1 \alpha$ in response to hypoxia, ${ }^{45}$ and posttranscriptional regulation as opposed to transcription initiation. ${ }^{46)}$ Taken together, our data suggest that SA attenuates hypoxia-induced repression of mTOR signaling through down-regulating the protein levels of HIF- $1 \alpha$ and REDD1 in PC12 cells. SA, acting as a 
a

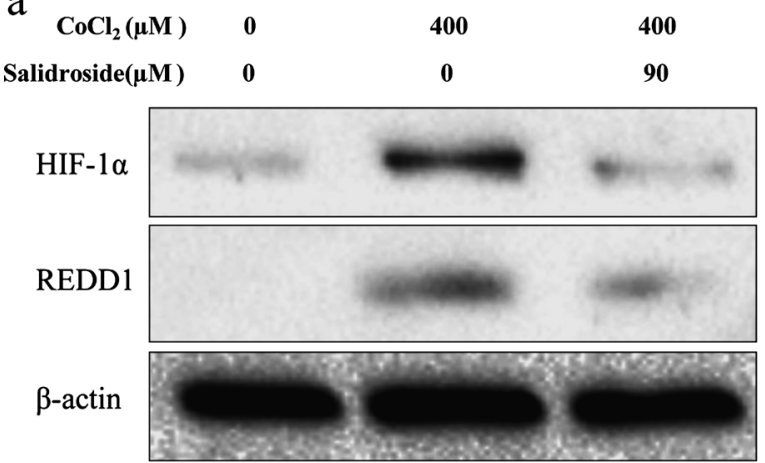

b

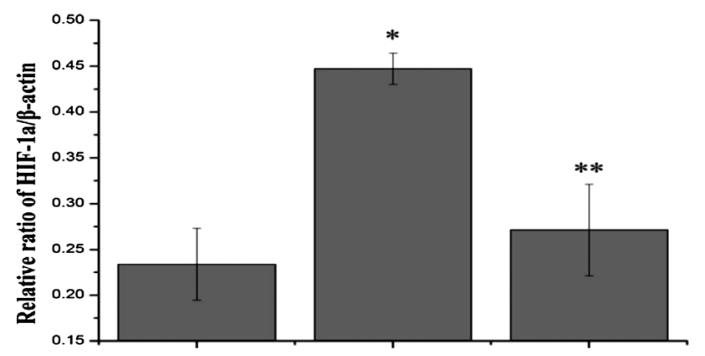

c

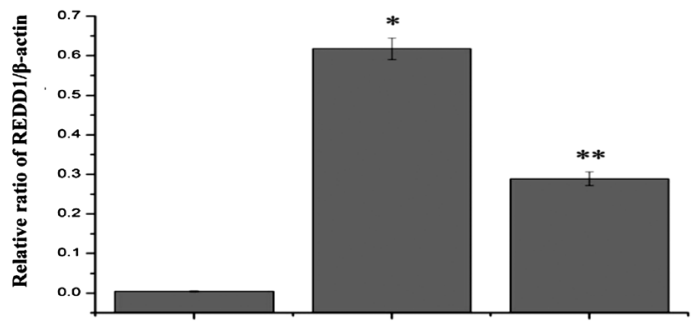

d

HIF- $1 \alpha$

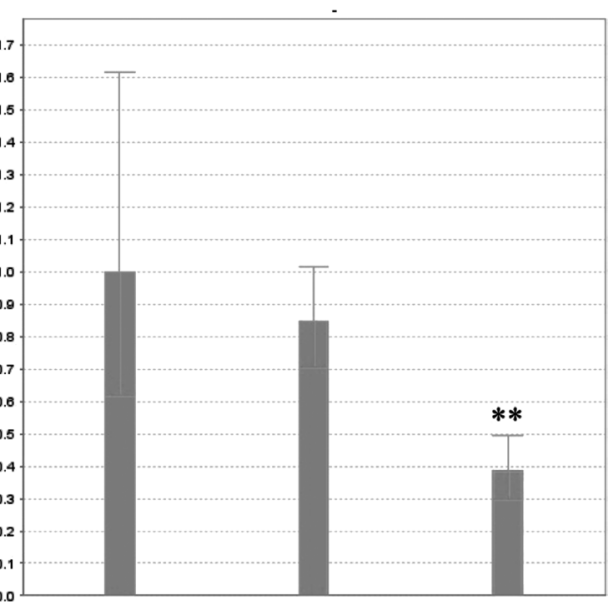

$\mathrm{CoCl}_{2}(\mu \mathrm{M})$

Salidroside $(\mu \mathrm{M})$
400

0
400

90

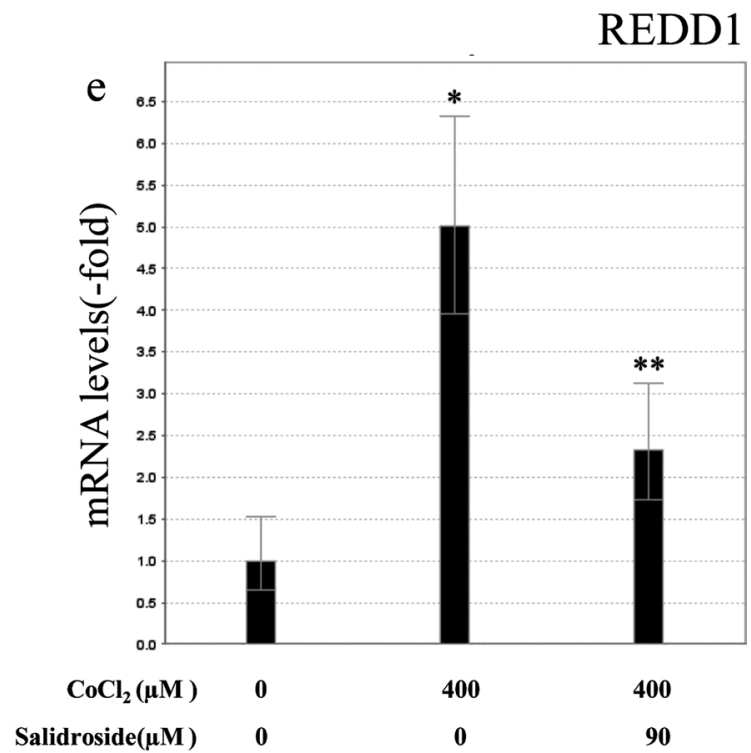

Fig. 4. Effect of SA on HIF-1 $\alpha$ and REDD1 Expression in PC12 Cells

HIF-1 $\alpha$ and REDD1 protein levels (a) measured by Western blot analysis. The results were evaluated by the ratio of densitometric unit and $\beta$-actin was used as loading control (b, c). Data are representatives of three independent experiments. mRNA level of HIF-1 $\alpha$ and REDD1 were determined by real-time PCR analysis (d, e). Data are normalized relative to P0 mRNA levels and the value for the control was considered as 1 . Each experiment was done in triplicate twice and data corresponding to the mean \pm S.E.M. of RNA from three different extractions. ${ }^{*} p<0.05$, compared with the control group (no treatment). ${ }^{* *} p<0.05$, compared with the group that treated with $\mathrm{CoCl}_{2}$ only.

neuroprotective drug, may limit ischemic neuronal death and promote neurological recovery via sustaining mTOR signal transduction. Interestingly, Liu et al. ${ }^{35)}$ reported that SA can decrease the growth of bladder cancer cell lines via inhibition of the mTOR pathway. As the mTOR pathway regulates many major cellular processes and is implicated in an increasing number of pathological conditions, including cancer, obesity, type 2 diabetes, and neurodegeneration, ${ }^{38)}$ we speculate that SA may exert a unique dual effect, protective for normal cells but toxic to tumor cells.

Additionally, our flow cytometry and electron microscopy data show that $\mathrm{CoCl}_{2}$ strongly stimulates ROS production in PC12 cells and causes drastic ultrastructural changes including swollen mitochondria with disintegration and lysis of cristae, which is consistent with the results by Zou et al. ${ }^{36)}$ Of note, our present study showed that SA can significantly attenuate the $\mathrm{CoCl}_{2}$-induced ultrastructural damage of mitochondria and ROS production. REDD1 is suggested to functions as a direct regulator of mitochondrial metabolism, and mediates a negative feedback pathway to HIF-1 $\alpha$ through regulation of ROS. ${ }^{34,47-50)}$ The drastic ultrastructural changes of mitochondria suggest that SA may act as a neuroprotective agent as well as a antioxidant to attenuate the $\mathrm{CoCl}_{2}$-induced mitochondrial dysfunction and ROS production, which in turn change the HIF- $1 \alpha$ stabilization and REDD1 expression, further sustaining mTOR signal transduction. Moreover, considering the drastic ultrastructural changes of mitochondria but not much decrease in ROS level in SA treatment group, we speculate that SA may play a more important role in neuroprotective effects than anti-oxidative effects during cerebral ischemia.

In conclusion, our results demonstrate that $\mathrm{SA}$ is able to at- 
a

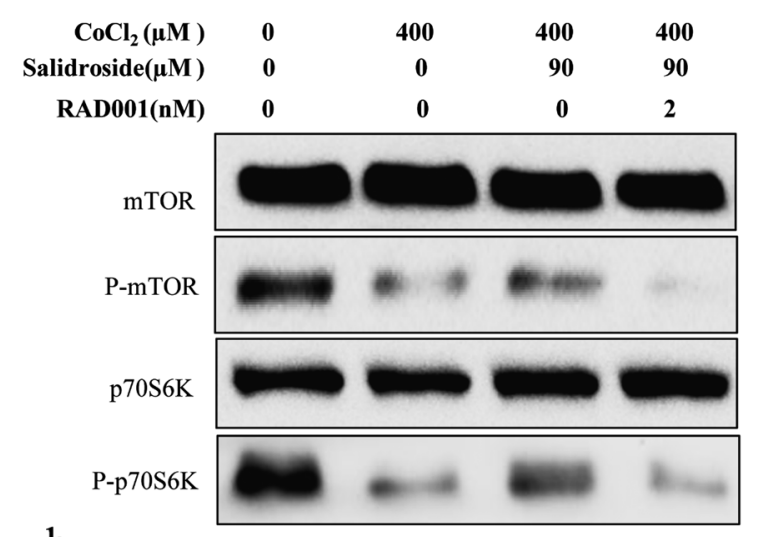

b
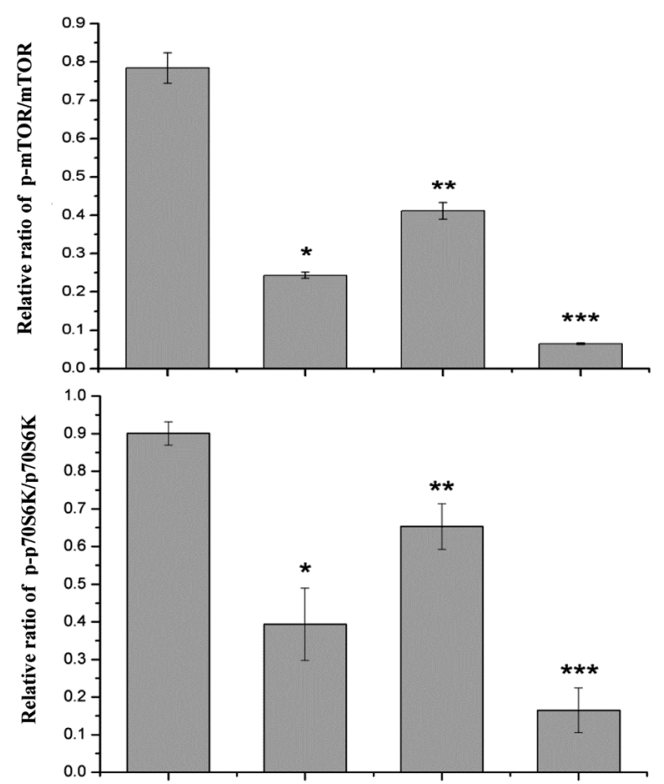

Fig. 5. Effect of $\mathrm{SA}$ on mTOR Signaling in $\mathrm{CoCl}_{2}$-Induced PC12 Cells

PC12 cells were pretreated with $2 \mathrm{nM}$ RAD001 for $2 \mathrm{~h}$ before being exposed to $400 \mu \mathrm{M} \mathrm{CoCl}{ }_{2}$ for an additional 12h. Phosphorylation status and levels of mTOR, p70S6K, were measured by Western blot (a). The results were evaluated by the ratio of densitometric unit $(\mathrm{b}, \mathrm{c})$. Data are representatives of three independen experiments. ${ }^{*} p<0.05$, compared with the control group (no treatment). ${ }^{*} p<0.05$, compared with the group that treated with $\mathrm{CoCl}_{2}$ only.. $* * * p<0.05$, compared with the group that treated with $\mathrm{CoCl}_{2}$ and SA.

tenuate $\mathrm{CoCl}_{2}$-induced hypoxia damage and mTOR signaling repression in PC12 cells, suggesting that SA may protect brain neurons from ischemic injury through sustaining mTOR activity, and provide a useful approach in prevention and treatment of ischemic stroke.

Acknowledgments This study was supported by Grants from the National Natural Science Foundation of China (No. 81273835). We thank Dr. Guangpu Li, University of Oklahoma Health Sciences Center, for critical reading of the manuscript.

\section{REFERENCES}

1) Chong ZZ, Yao Q, Li HH. The rationale of targeting mammalian target of rapamycin for ischemic stroke. Cell. Signal., 25, 15981607 (2013).

2) Laplante M, Sabatini DM. mTOR signaling in growth control and disease. Cell, 149, 274-293 (2012).

3) Arsham AM, Howell JJ, Simon MC. A novel hypoxia-inducible fac- tor-independent hypoxic response regulating mammalian target of rapamycin and its targets. J. Biol. Chem., 278, 29655-29660 (2003).

4) Hernández-Jimenez M, Ayuso MI, Perez-Morgado MI, GarciaRecio EM, Alcazar A, Martin ME, Gonzalez VM. eIF4F complex disruption causes protein synthesis inhibition during hypoxia in nerve growth factor (NGF)-differentiated PC12 cells. Biochim. Biophys. Acta, 1823, 430-438 (2012).

5) Shoshani $T$, Faerman A, Mett I, Zelin E, Tenne T, Gorodin S, Moshel Y, Elbaz S, Budanov A, Chajut A, Kalinski H, Kamer I, Rozen A, Mor O, Keshet E, Leshkowitz D, Einat P, Skaliter R, Feinstein E. Identification of a novel hypoxia-inducible factor 1-responsive gene, RTP801, involved in apoptosis. Mol. Cell. Biol., 22, 2283-2293 (2002).

6) Regazzetti C, Bost F, Le Marchand-Brustel Y, Tanti JF, GiorgettiPeraldi S. Insulin induces REDD1 expression through hypoxiainducible factor 1 activation in adipocytes. J. Biol. Chem., 285, 5157-5164 (2010).

7) Wang G, Hazra TK, Mitra S, Lee HM, Englander EW. Mitochondrial DNA damage and a hypoxic response are induced by $\mathrm{CoCl}_{2}$ in rat neuronal PC12 cells. Nucleic Acids Res., 28, 2135-2140 (2000).

8) Chandel NS, Maltepe E, Goldwasser E, Mathieu CE, Simon MC, Schumacker PT. Mitochondrial reactive oxygen species trigger hypoxia-induced transcription. Proc. Natl. Acad. Sci. U.S.A., 95, 11715-11720 (1998).

9) Reimann-Philipp U, Ovase R, Weigel PH, Grammas P. Mechanisms of cell death in primary cortical neurons and PC12 cells. J. Neurosci. Res., 64, 654-660 (2001).

10) Hillion JA, Takahashi K, Maric D, Ruetzler C, Barker JL, Hallenbeck JM. Development of an ischemic tolerance model in a PC12 cell line. J. Cereb. Blood Flow Metab., 25, 154-162 (2005).

11) Hou RC, Huang HM, Tzen JT, Jeng KC. Protective effects of sesamin and sesamolin on hypoxic neuronal and PC12 cells. J. Neurosci. Res., 74, 123-133 (2003).

12) Jung JY, Mo HC, Yang KH, Jeong YJ, Yoo HG, Choi NK, Oh WM, Oh HK, Kim SH, Lee JH, Kim HJ, Kim WJ. Inhibition by epigallocatechin gallate of $\mathrm{CoCl}_{2}$-induced apoptosis in rat $\mathrm{PC1} 2$ cells. Life Sci., 80, 1355-1363 (2007).

13) Díaz Lanza AM, Abad Martínez MJ, Fernández Matellano L, Recuero Carretero C, Villaescusa Castillo L, Silván Sen AM, Bermejo Benito P Lignan and phenylpropanoid glycosides from Phillyrea latifolia and their in vitro anti-inflammatory activity. Planta Med., 67, 219-223 (2001).

14) Iaremii IN, Grigor'eva NF. Hepatoprotective properties of liquid extract of Rhodiola rosea. Eksp. Klin. Farmakol., 65, 57-59 (2002).

15) De Sanctis R, De Bellis R, Scesa C, Mancini U, Cucchiarini L, Dacha M. In vitro protective effect of Rhodiola rosea extract against hypochlorous acid-induced oxidative damage in human erythrocytes. Biofactors, 20, 147-159 (2004).

16) Kucinskaite A, Briedis V, Savickas A. Experimental analysis of therapeutic properties of Rhodiola rosea $\mathrm{L}$. and its possible application in medicine. Medicina (Kaunas), 40, 614-619 (2004).

17) Mattioli L, Perfumi M. Rhodiola rosea L. extract reduces stressand CRF-induced anorexia in rats. J. Psychopharmacol., 21, 742750 (2006).

18) Perfumi M, Mattioli L. Adaptogenic and central nervous system effects of single doses of $3 \%$ rosavin and $1 \%$ salidroside Rhodiola rosea L. extract in mice. Phytother. Res., 21, 37-43 (2007).

19) Kanupriya, Prasad D, Sai Ram M, Kumar R, Sawhney RC, Sharma SK, Ilavazhagan G, Kumar D, Banerjee PK. Cytoprotective and antioxidant activity of Rhodiola imbricata against tert-butyl hydroperoxide induced oxidative injury in U-937 human macrophages. Mol. Cell. Biochem., 275, 1-6 (2005).

20) Zou YQ, Cai ZY, Mao YF, Li JB, Deng XM. Effects of salidrosidepretreatment on neuroethology of rats after global cerebral ischemia-reperfusion. Zhong Xi Yi Jie He Xue Bao, 7, 130-134 (2009). 21) Chen SF, Tsai HJ, Hung $\mathrm{TH}$, Chen $\mathrm{CC}$, Lee $\mathrm{CY}, \mathrm{Wu} \mathrm{CH}$, Wang 
PY, Liao NC. Salidroside improves behavioral and histological outcomes and reduces apoptosis via PI3K/Akt signaling after experimental traumatic brain injury. PLoS ONE, 7, e45763 (2012).

22) Qu ZQ, Zhou Y, Zeng YS, Lin YK, Li Y, Zhong ZQ, Chan WY. Protective effects of a Rhodiola crenulata extract and salidroside on hippocampal neurogenesis against streptozotocin-induced neural injury in the rat. PLoS ONE, 7, e29641 (2012).

23) Zhu Y, Shi YP, Wu D, Ji YJ, Wang X, Chen HL, Wu SS, Huang DJ, Jiang W. Salidroside protects against hydrogen peroxide-induced injury in cardiac H9c2 cells via PI3K-Akt dependent pathway. DNA Cell Biol., 30, 809-819 (2011).

24) Shi TY, Feng SF, Xing JH, Wu YM, Li XQ, Zhang N, Tian Z, Liu $\mathrm{SB}$, Zhao MG. Neuroprotective effects of salidroside and its analogue tyrosol galactoside against focal cerebral ischemia in vivo and $\mathrm{H}_{2} \mathrm{O}_{2}$-induced neurotoxicity in vitro. Neurotox. Res., 21, 358-367 (2012).

25) Chen X, Liu J, Gu X, Ding F. Salidroside attenuates glutamateinduced apoptotic cell death in primary cultured hippocampal neurons of rats. Brain Res., 1238, 189-198 (2008).

26) Chen $X$, Zhang Q, Cheng Q, Ding F. Protective effect of salidroside against $\mathrm{H}_{2} \mathrm{O}_{2}$-induced cell apoptosis in primary culture of rat hippocampal neurons. Mol. Cell. Biochem., 332, 85-93 (2009).

27) Zhang S, Chen X, Yang Y, Zhou X, Liu J, Ding F. Neuroprotection against cobalt chloride-induced cell apoptosis of primary cultured cortical neurons by salidroside. Mol. Cell. Biochem., 354, 161-170 (2011).

28) Tan CB, Gao M, Xu WR, Yang XY, Zhu XM, Du GH. Protective effects of salidroside on endothelial cell apoptosis induced by cobalt chloride. Biol. Pharm. Bull., 32, 1359-1363 (2009).

29) Yu S, Liu M, Gu X, Ding F. Neuroprotective effects of salidroside in the PC12 cell model exposed to hypoglycemia and serum limitation. Cell. Mol. Neurobiol., 28, 1067-1078 (2008).

30) Zhao Y, Ling Y, Zhao J, Yuan Y, Guo Y, Liu Q, Wu B, Ding Z, Yang Y. Synthesis and protective effects of novel salidroside analogues on glucose and serum depletion induced apoptosis in $\mathrm{PC12}$ cells. Arch. Pharm. (Weinheim), 346, 300-307 (2013).

31) Yu S, Shen Y, Liu J, Ding F. Involvement of ERK1/2 pathway in neuroprotection by salidroside against hydrogen peroxide-induced apoptotic cell death. J. Mol. Neurosci., 40, 321-331 (2010).

32) Zhang L, Yu H, Sun Y, Lin X, Chen B, Tan C, Cao G, Wang Z. Protective effects of salidroside on hydrogen peroxide-induced apoptosis in SH-SY5Y human neuroblastoma cells. Eur. J. Pharmacol., 564, 18-25 (2007).

33) Zhang L, Yu H, Zhao X, Lin X, Tan C, Cao G, Wang Z. Neuroprotective effects of salidroside against beta-amyloid-induced oxidative stress in SH-SY5Y human neuroblastoma cells. Neurochem. Int., 57, 547-555 (2010)

34) Xu MC, Shi HM, Wang H, Gao XF. Salidroside protects against hydrogen peroxide-induced injury in HUVECs via the regulation of REDD1 and mTOR activation. Mol. Med. Rep., 8, 147-153 (2013).

35) Liu Z, Li X, Simoneau AR, Jafari M, Zi X. Rhodiola rosea extracts and salidroside decrease the growth of bladder cancer cell lines via inhibition of the mTOR pathway and induction of autophagy. Mol. Carcinog., 51, 257-267 (2012).

36) Zou W, Yan M, Xu W, Huo H, Sun L, Zheng Z, Liu X. Cobalt chloride induces $\mathrm{PC} 12$ cells apoptosis through reactive oxygen species and accompanied by AP-1 activation. J. Neurosci. Res., 64, 646-653 (2001).

37) Roger VL, Go AS, Lloyd-Jones DM, Adams RJ, Berry JD, Brown
TM, Carnethon MR, Dai S, de Simone G, Ford ES, Fox CS, Fullerton HJ, Gillespie C, Greenlund KJ, Hailpern SM, Heit JA, Ho PM, Howard VJ, Kissela BM, Kittner SJ, Lackland DT, Lichtman JH, Lisabeth LD, Makuc DM, Marcus GM, Marelli A, Matchar DB, McDermott MM, Meigs JB, Moy CS, Mozaffarian D, Mussolino ME, Nichol G, Paynter NP, Rosamond WD, Sorlie PD, Stafford RS, Turan TN, Turner MB, Wong ND, Wylie-Rosett J, Roger VL, Turner MB; American Heart Association Statistics Committee and Stroke Statistics Subcommittee. Heart disease and stroke statistics-2011 update: a report from the American Heart Association. Circulation, 123, e18-e209 (2011).

38) Jastrzebski K, Hannan KM, Tchoubrieva EB, Hannan RD, Pearson RB. Coordinate regulation of ribosome biogenesis and function by the ribosomal protein S6 kinase, a key mediator of mTOR function. Growth Factors, 25, 209-226 (2007).

39) Koh PO, Cho JH, Won CK, Lee HJ, Sung JH, Kim MO. Estradiol attenuates the focal cerebral ischemic injury through mTOR/p70S6 kinase signaling pathway. Neurosci. Lett., 436, 62-66 (2008).

40) Pastor MD, Garcia-Yebenes I, Fradejas N, Perez-Ortiz JM, MoraLee S, Tranque P, Moro MA, Pende M, Calvo S. mTOR/S6 kinase pathway contributes to astrocyte survival during ischemia. J. Biol. Chem., 284, 22067-22078 (2009).

41) Chong ZZ, Shang YC, Zhang L, Wang S, Maiese K. Mammalian target of rapamycin: hitting the bull's-eye for neurological disorders. Oxid. Med. Cell. Longev., 3, 374-391 (2010).

42) Chong ZZ, Li F, Maiese K. The pro-survival pathways of mTOR and protein kinase $\mathrm{B}$ target glycogen synthase kinase-3beta and nuclear factor-kappaB to foster endogenous microglial cell protection. Int. J. Mol. Med., 19, 263-272 (2007).

43) Shang YC, Chong ZZ, Wang S, Maiese K. Tuberous sclerosis protein 2 (TSC2) modulates CCN4 cytoprotection during apoptotic amyloid toxicity in microglia. Curr. Neurovasc. Res., 10, 29-38 (2013).

44) Shang YC, Chong ZZ, Wang S, Maiese K. Erythropoietin and Wnt1 govern pathways of mTOR, Apaf-1, and XIAP in inflammatory microglia. Curr. Neurovasc. Res., 8, 270-285 (2011).

45) Jewell UR, Kvietikova I, Scheid A, Bauer C, Wenger RH, Gassmann M. Induction of HIF-1alpha in response to hypoxia is instantaneous. FASEB J., 15, 1312-1314 (2001).

46) Kim JE, Chen J. Cytoplasmic-nuclear shuttling of FKBP12-rapamycin-associated protein is involved in rapamycin-sensitive signaling and translation initiation. Proc. Natl. Acad. Sci. U.S.A., 97, 1434014345 (2000).

47) Mansfield KD, Guzy RD, Pan Y, Young RM, Cash TP, Schumacker PT, Simon MC. Mitochondrial dysfunction resulting from loss of cytochrome $c$ impairs cellular oxygen sensing and hypoxic HIFalpha activation. Cell Metab., 1, 393-399 (2005).

48) Guzy RD, Hoyos B, Robin E, Chen H, Liu L, Mansfield KD, Simon MC, Hammerling U, Schumacker PT. Mitochondrial complex III is required for hypoxia-induced ROS production and cellular oxygen sensing. Cell Metab., 1, 401-408 (2005).

49) Brunelle JK, Bell EL, Quesada NM, Vercauteren K, Tiranti V, Zeviani M, Scarpulla RC, Chandel NS. Oxygen sensing requires mitochondrial ROS but not oxidative phosphorylation. Cell Metab., 1, 409-414 (2005).

50) Horak P, Crawford AR, Vadysirisack DD, Nash ZM, DeYoung MP, Sgroi D, Ellisen LW. Negative feedback control of HIF-1 through REDD1-regulated ROS suppresses tumorigenesis. Proc. Natl. Acad. Sci. U.S.A., 107, 4675-4680 (2010). 